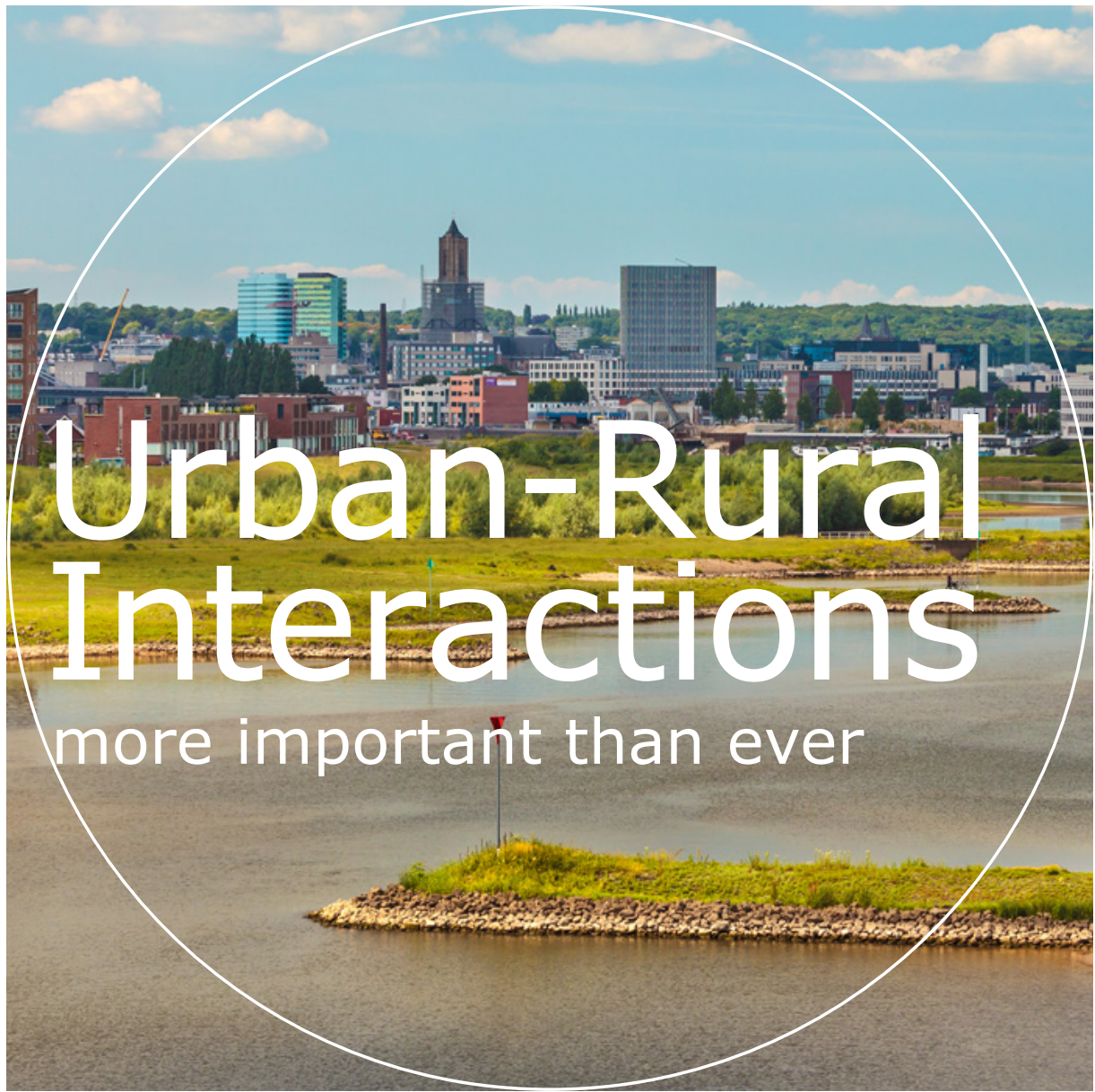

Prof.dr Eveline S. van Leeuwen

Inaugural lecture upon taking up the position of Professor of Urban Economics at Wageningen University \& Research on 13 September 2018 



\section{Urban-Rural Interactions more important than ever}

\section{Prof.dr Eveline S. van Leeuwen}

Inaugural lecture upon taking up the position of Professor of Urban Economics at Wageningen University \& Research on 13 September 2018 
DOI https://doi.org/10.18174/508329

ISBN 978-94-6395-236-1

(C)2019 Prof.dr Eveline S. van Leeuwen. All rights reserved. No parts of this publication may be reproduced by print, photocopy, stored in a retrieval system or transmitted by any means without the prior written permission of the author. 


\section{Urban-Rural Interactions} more important than ever

Esteemed Rector Magnificus,

Distinguished colleagues, dear students, dear family and friends, ladies and gentlemen,

Cities are great, really they are! They are places of development, of innovation and creativity. In many urban areas labour productivity is higher compared to the rest of the country and many innovations started within the urban context. According to the Worldbank (2018), around $55 \%$ of the population lives in urban areas, producing $80 \%$ of our global GDP. In addition, they occupy only $3 \%$ of the world surface and they use $75 \%$ of our global resources (UNEP, 2011)

In the developing world, cities are often seen as places of hope: hope of finding a job, hope of finding a better life. And indeed, in those areas, cities provide higher job opportunities, higher life-expectancy rates and higher levels of life-satisfaction for their residents than their rural counterparts.

In addition, cities are seen as places of change. Thanks to their compact geography and the critical mass of the population, pro-active municipalities can really make a different through their policies and regulations and provide great opportunities for large-scale experiments. Take for example the cities of San Francisco, New York and closer to home Amsterdam, who, with their citizens, aim to be at the forefront of sustainable development ${ }^{1}$.

\section{Economists love cities}

Economists also love cities, in particular urban and regional economists (see e.g. Glaeser, 2011). They show a great interest in the so-called agglomeration advantages: advantages that arise thanks to the high density of both firms and consumers in a relatively small area.

\footnotetext{
1 Amsterdam committed to be 50\% circular in 2050 (Gladek, 2017); New York committed to reducing green-house gasses $80 \%$ by 2050 and to achieve zero-waste by 2030 (OneNYC, 2018); San Francisco already recycles or reuses $80 \%$ of her waste (Silva et al., 2017).
} 
Because of this high density, distances are short and travel costs relatively low. This can result in economics of agglomeration, i.e. lower average costs of production when higher levels of production take place in a certain geographical area (Anas et al., 1998). Cities inhabit a great labour market: the large number of firms located in the urban area can rely on a large number of nearby workers. The diversity in both firms and workers also results in general in a good match between supply and demand for labour skills: when a firm needs a specific type of skilled worker, i.e. certain computer, language or technical skills, then the chances of finding someone in the urban context is much larger than in a rural area. Similar advantages arise in the consumer market: thanks to the heterogeneous urban population, there is room for all kinds of retail services: mainstream and exotic,

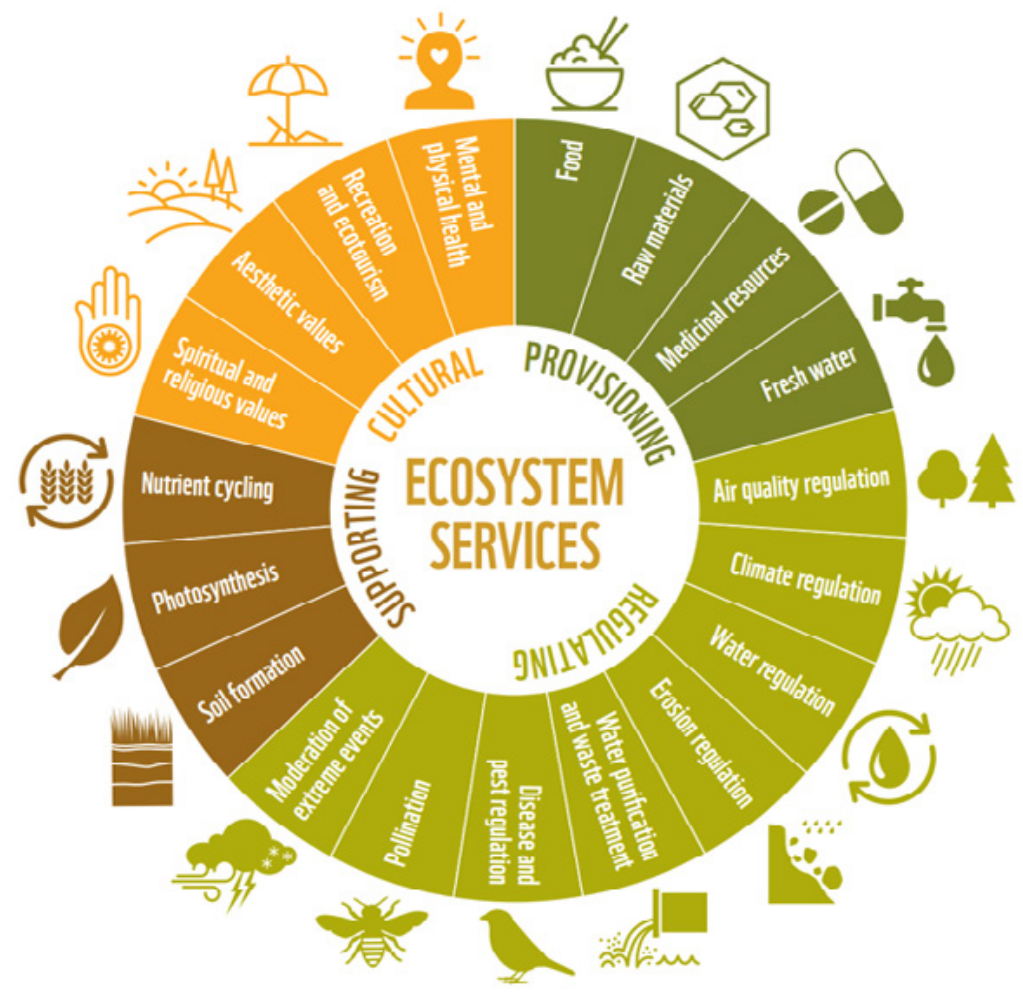

ECOSYSTEM SERVICES

Provisioning services are the products obtained from ecosystems.

Regulating services are the benefits obtained from the regulation of ecosystem processes.

Cultural services are the nonmaterial benefits people obtain from ecosystems.

Supporting services are those services that are necessary for the production of all other ecosystem services.

Figure 1: Ecosystem services Source: WWF Living Planet Report 2016 
small and large store, for daily or fun shopping activities. In addition, several services, for which a relatively large number of customers is required, are in general located in cities. Think of theatres, universities or hospitals. This diversity in supply of consumer goods and services, which can be seen as an urban amenity (Garretsen and Marlet, 2017), attracts in itself new people to the city. People that interact, exchange ideas and by doing so create urban buzz and potentially facilitate knowledge spill-overs that are beneficial for social and technical innovations. In other words, cities are great places for 'sharing, matching and learning' (Puga, 2010).

But, cities are not islands - or even networks of islands. Although it seems that urban residents, urban scholars or urban politicians often prefer to believe otherwise, cities are always connected to rural regions, both nearby and far away. "The growing urban population even "quite literally means" that a growing share of the world's population depends on rural places for the provision of food, energy and recreation' (Lichter and Brown 2011, p.567).

So what are the advantages of rural areas? Perhaps we could call them capacity advantages? I am open to alternative labels during the reception this afternoon. But in any way, rural areas have the advantages of space. Space for large-scale industries, for infrastructure, and for renewable and non-renewable energy sources. But even more importantly, rural areas have space for ecosystems (see Figure 1). And similar to certain economic activities, ecosystems also benefit from economies of scale: many natural processes are much more efficient if they have enough space. Space for plants to purify the air, space for groundwater systems to purify our water, space for ecosystems to house rare species, space for rivers to prevent flooding downstream where most cities are located and space for providing us with food and fibre that we need for our daily consumption. As you see, these are all services of ecosystems that are indispensable for a healthy earth, a healthy society and healthy cities.

\section{Urban-rural interactions}

Of course, urban-rural interactions are not completely absent in the economics literature. In particular in regional economics, there is an interesting track of the literature that builds on the concepts of Von Thünen (1826) about the relationship between cities and the surrounding types of land-use, Walter Christaller (1966) and his central place theory related to (consumer) services, and more recently, Paul Krugman and his core-periphery model (Krugman, 1991) which laid the foundation for his 2008 Nobel Prize. 
Economic linkages between regions can be subdivided in goods and factor mobility. Goods mobility often takes place in the form of trade, factor mobility in the form of migration/commuting of workers and the mobility of capital (Helpman, 1998). However, not all resources are mobile. Important examples of immobile resources are social capital, cultural capital and environmental capital (Terluin, 2003). In order to benefit from these, either firms or workers need to move towards them. As a result, the interactions often result in labour flows, consumption flows, product flows and tourism flows (van Leeuwen, 2010). We only have to listen to the radio in the morning to hear about the large flows of commuters travelling between cities, as well as between urban and rural areas. In addition, large amounts of people move to the city centres for shopping purposes, others travel from the city to visit specific stores in rural areas (van Leeuwen and Rietveld, 2011). When we order stuff online, it is more difficult to know where it comes from, but increasingly, the Internet allows entrepreneurs in the countryside to reach urban customers (Herslund, 2012). Urban residents also like to visit the countryside for a relaxing walk, bike or boat trip or to visit a specific museum. Rural people visit cities to enjoy entertainment provided by concert halls and theatres (van Leeuwen, 2015). Just look at the city centres of Amsterdam, Giethoorn or Schiermonnikoog that are packed with tourists from all over the Netherlands, and all over the world.

In general, those interactions are considered positive. It results in economically resilient regions, thanks to a more diverse economy, a flexible labour market and knowledge spill-overs. This is for example shown by Lewis Dijkstra and colleagues (2015) in their study of European Regions before, during and after the financial crisis of 2008. They find that post-crisis rural areas close to cities and intermediate areas are the most robust types of European regions: they suffered less from the recent financial crisis and they recovered more quickly compared to their urban and remote rural counterparts.

In a recent study by Daniel Arribas-Bel from the University of Liverpool and myself we look at the relationship between urban-rural interactions and economic performance in terms of population, income and employment growth. Taking into account 1075 European NUTS 3 regions between 2000-2007, we estimate the effect of proximity to regions that differ in the level of urbanity, while controlling for the sectoral and spatial configuration within the regions, e.g. sector composition, clustering of urban population and distance to a large city. Interestingly, we find that the effects go both ways. In most regional growth models, the focus is on urban centres as the places of cumulative causation or 'engines of growth' (Gruber and Soci, 2010), and urban economic growth is expected to trickle down to the rural economies. Relationships are often considered asymmetrical. However, our study 
shows that interactions are (increasingly) symmetrical with mutual interdependencies: intermediate and urban regions benefit from the vicinity of rural regions in terms of employment growth and rural areas benefit from urban neighbours. When looking at GDP growth, we see that rural areas that neighbour urban and intermediate areas face higher income growth. However, urban areas do not seem to benefit from nearby rural areas in terms of GDP growth. But, they do benefit from rural areas when looking at population growth, and this relationship is again reciprocal since also intermediate and rural areas near cities face a larger influx of residents.

\section{Urban-rural interactions in terms of energy and nutrient linkages} Interesting stuff, but I argue that we need to go beyond these more traditional interactions and focus more on urban-rural interactions in terms of energy and nutrient linkages. Renewable energy has become an essential part of the solution to a number of issues, from climate change and air pollution to geopolitical risks, and local and regional economic development. For many renewable energy sources we need space - space for windmills, solar panels, bio refineries and the production of biomass. Space that rural areas can offer. For circularity, including circular agriculture, the collection of waste and the re-use and recycling of materials is important. In addition, a physical link between the (food) waste of consumers and the water and nutrient cycles is indispensable. In many places rural goods and services are increasingly targeting urban consumers/business, allowing rural regions to benefit from urban growth (Lichter and Brown, 2011). However, these benefits often suffer from distance decay and may be less promising for more remote rural regions. With the current challenges of the energy transition and circular society, there might be opportunities for remote regions as well. Just picture the current situation in which food is produced in rural Africa, transported to the Netherlands, consumed by urban residents and incinerated just outside Amsterdam. This is a linear system. And when we consider the shortage of nutrients in the place of origin and the redundancy of (certain) nutrients in our country, and the related problems in both regions, it is clearly unsustainable. This example illustrates the need to close the cycles and the urge for a renewed focus on urban-rural interactions at the local, regional and global level.

In order to study these types of vital urban-rural interactions we need better insights into cycles and flows and opportunities for (physical) linkages. As such, it is very important to increase our knowledge of technological solutions. Technical solutions to recycle and re-use domestic and industrial waste-water and solutions to better recycle and re-use food waste and nutrients. As well as solutions for large scale energy systems and the ability to transport and store energy without too high 
losses. For these insights I trust on the skills and creativity of technical engineers, on the many excellent scientists here in Wageningen, as well as at other technical universities in the Netherlands and all over the world.

Urban and regional economists are called upon to address the spatial consequences of these transformations. If we think about circularity we need connections to the cycles in both rural and urban areas. What does this mean for the spatial allocation of activities and processes, and in which way is this efficient from an economical, ecological and social perspective? These issues have not been studied systematically yet.

But, technology alone will not save us. People themselves need to change, to adapt as well. Therefore, we need better insights in the motivation and behaviour of citizens. How can we activate the urban population? And the rural population? How can we seduce them to actively participate in energy saving, recycling, et cetera? To accept that developments will be located in their backyard? And how can we avoid sentiments of inequality that increasingly result in protest voices and destabilize our societies, because certain groups of people feel they are not represented or not heard by (national) policy makers, as we saw happening in the United Kingdom, the United States and to some extent also in the Netherlands.

For that, we need to realize that urban-rural differences exist and that they matter.

Differences appear and remain due to differences in spatial opportunities and constraints, as well as due to differences in the types of people and households living in urban and rural areas. Next, I want to focus a bit more on these differences.

\section{Different circumstances, or different people?}

We all have our own connotations about the differences between urban and rural areas. These are based on our personal experiences, about what we see in the media and read in the newspapers or literature. Often, this information is quite biased. In fact, many people have no direct experience with rural people and communities but encounter rural images, themes, and/or stereotypes mostly through the arts, media, and literature (de Souza, 2018; Lichter and Brown, 2011). This means, that often our image of 'the rural' is not in line with reality.

And to illustrate this, information collected by Eurostat is very useful. Based on regional statistics they madk a distinction between people living in rural (the green dots), intermediate (the orange dots) and urban areas (the blue dots). The Yearbook of 2015 shows that in most member states of the European Union, except Malta, the 

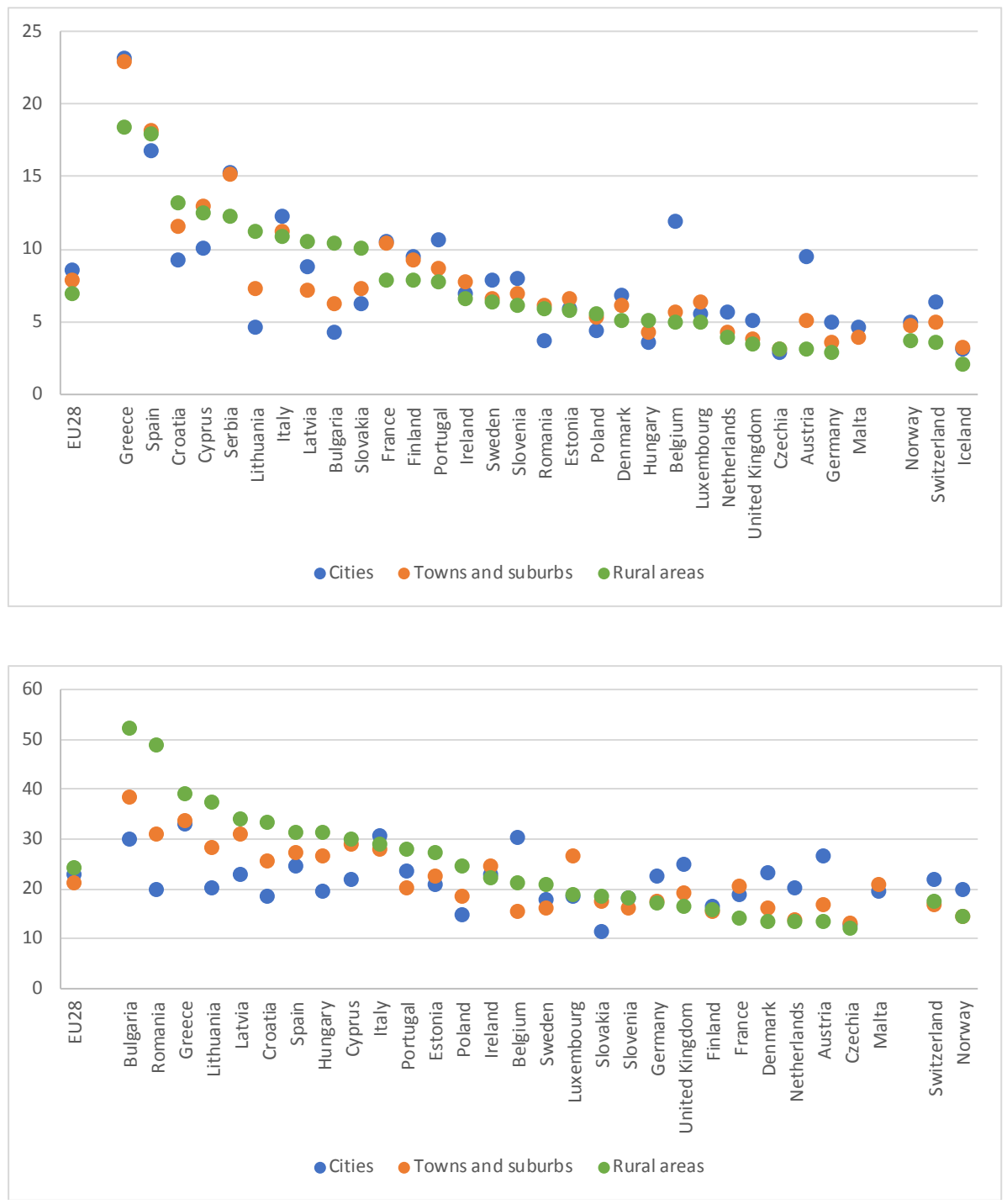

Figure 2 and 3: Unemployment rates of persons aged 15-74 (2) and being at risk of poverty or social exclusion (3) by degree of urbanisation in 2015. Source: Eurostat

share of young people (between 18 and 34 years old) with a high education level is the highest in urban areas. Cities are in general attractive for people to study, but also for young people to find their first job. This image is in line with what most people expect. In addition, when looking at unemployment or the risk of people to 
encounter poverty or social exclusion, we might expect that this is also more likely in urban areas.

Figures 2 and 3 show for each EU member state the difference between urban, intermediate, and rural regions in terms of unemployment rates and poverty and social exclusion. Figure 2 shows the unemployment rates in urban and rural regions. We see a clear divide between EU countries when sorting them based on unemployment levels in rural areas. At the left side we see the newer member states, such as Bulgaria and Croatia, where unemployment levels are (very) high in the rural areas and much lower in the urban areas. However, for the older member states, such Austria, Germany and also the Netherlands it is the other way around: the highest unemployment levels are found in the cities. A similar picture arises when we look at poverty and social exclusion in Figure 3.

These graphs show how urban and rural characteristics differ between countries: in the economically developed countries, differences are smaller and often in favour of rural areas. In the less developed countries, it is the cities where welfare improvements started, and where living circumstances are often better compared to rural areas. This is also confirmed by more in-depth studies that look for example at health and life expectancy (Koster et al., 2017) or life satisfaction (Sørensen, 2014). In developing countries, cities can really be seen as places of hope and improvement, while in the more industrially developed countries people in rural areas are often better off.

Can we then also say that people in urban and rural areas are different, or is it mainly the circumstances that are different? In several countries, cultural differences are declining. Innovations, such as telecommunication, internet and high-speed transport have brought the urban into the rural and vice versa. However, certain differences remain. Resulting from: 1 ) sorting of people due to constraints and preferences; 2) different external factors affecting choices.

Sorting invokes the (non-random) clustering of similar people into areas where their (similar) preferences are best met. Some people prefer liveliness and high density of amenities such as shops and bars while others prefer space, green and quietness. Another reason for urban-rural sorting is related to jobs and wages: in cities there are generally more job opportunities for highly educated people with higher wages compared to rural areas. While for lower educated persons the wage differences are much smaller and do not outweigh the (social and economic) costs of moving. However, sorting does not always happens on a voluntary basis; it is not only related to preferences. Some people stay behind, are locked in, they cannot 
move even though they would like to migrate to a different place. Not only in Africa or Asia, but also in Eastern Europe, it is mainly the weak and the old that have no option to move to a better future in the city. They have to remain in the countryside and work hard for their bread or rice. In Europe and the US we can think of people that would like to move out of areas of decline, but are locked in because of the inability to sell their house (Molloy et al., 2011).

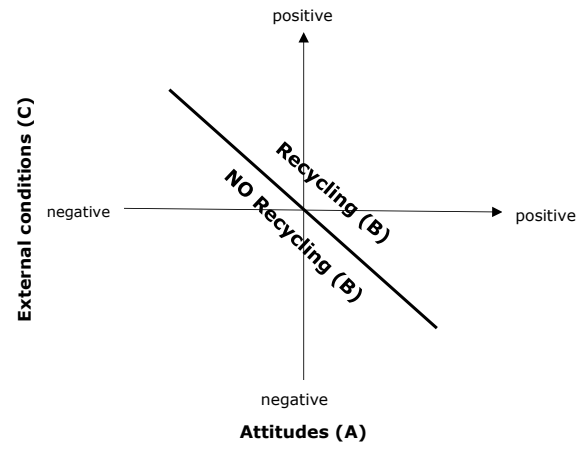

Figure 4: The attitude-behaviour-context model applied to recycling (source: Jackson, 2005, based on Stern, 2000)
Both this voluntary and involuntary sorting leads to socio-economic differences between the urban and rural population. In addition, socioenvironmental differences result in different behavior (through different reference points, attitudes, social norms) of otherwise similar people. This is also stressed by Stern and colleagues in their ABC, attitudebehaviour-context, model (Stern, 2000). As shown in Figure 4, depending on personal attitudes (often referred to as preferences in

the economics literature) and external (physical and/or social) conditions, an individual exhibits certain behavior, for example recycling, or not. When access to recycling facilities is either very limited or very good, it almost does not matter whether or not people hold pro-recycling attitudes, you always find a corner solution: either no-one recycles or most people recycle. In a situation, however, in which it is possible but not necessarily easy to recycle, the correlation between pro-environmental attitude and recycling behaviour is strongest (Stern 2000; Jackson, 2005).

Although in (micro-) economics preferences are generally exogenous and seen as something that is inherited and fixed, in reality they are dynamic and related to the social and physical context. Preferences, or attitudes for that matter, can change because of new insights, new experiences, or new role-models. I myself, for example, lived in the city of Utrecht for 10 years. We lived in a high-density area with limited parking spaces and a lot of concrete. Often the noise and air pollution of traffic was clearly perceivable. I did not need to own a car; my bike and public transport card were enough. Also, I did not want to own a car mostly for environmental reasons. But, five years ago, we moved to Maarn, a little town in the forest, 20 minutes east from Utrecht. Public transport options were less ample, the 
air feels clean and you don't see any cars because they are all parked on the green drives. So, I bought a car-it is fully electric I must add - and try to use it as little as possible. However, it is more convenient than I expected. This example shows how a person with a similar pro-environmental attitude, makes different choices in an urban vs a rural context, in this case due to an update of her attitudes related to the environmental impact of cars, as well as due to changing physical circumstances.

Indeed, several of the limited number of studies that focus on urban-rural differences, found that both pro-environmental attitudes as well as behavior differs between urban and rural residents. Huddart-Kennedy et al. (2009), for example, found that urban residents score higher on pro-environmental behaviour, rural residents more on environmental concern. However, he also indicated that some of the rural environmental attitudes and behaviours (such a growing your own food) might not be part of most measurement methods (often composed by urban academics). Sarvilinna et al. (2018) found that urban residents are more willing to pay while rural people are more willing to volunteer. Unfortunately, in the literature there is a limited focus on urban-rural differences in attitudes and behaviour. This is an interesting research gap, and highly relevant for the development of interventions and policies and to understand what works in which place.

\section{Research agenda: People AND Places}

First of all, I want to stress that my research agenda is strongly embedded in the mission of the Urban Economics chair group. That mission is "to contribute to more resilient cities and regions in terms of social equality, economic advantages and environmental quality". We aim to do so by using insights from general, urban and behavioural economics to improve the understanding of consumer and household decision-making and the spatial impacts of these choices at the individual, urban and regional level.

Differences, between spatial units, and in particular between urban and rural areas are important, and as mentioned earlier, we are often not well aware of them. The fact that academics and decision-makers are mostly urbanites condition their perceptions of rural areas and their potential for our future. So my mission is "to create better insights in urban-rural differences, in order to promote urban-rural interactions." By doing so, I want to contribute to the UN development goals Sustainable cities and communities; Responsible consumption and production; and Partnerships for the goals.

In order to obtain new and relevant insights I will focus on people AND on places, 

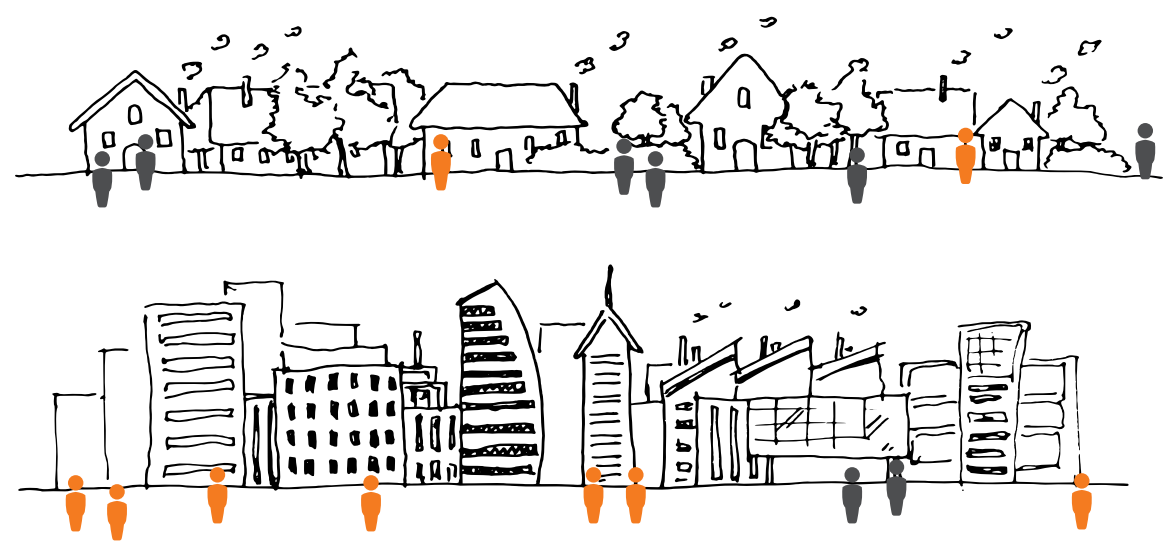

Figure 5: different people in different places

and thus take a micro and a macro approach. In economics, micro entails the study of the behaviour of individual economic units. The great advantage is the level of detail and the possibility of looking at 'real' behaviour. We can focus on people with all their differences, small and large, and obtain detailed insights into their often irrational behaviour in the context of a specific spatial environment. The disadvantage is, however, that it is difficult to measure indirect and redistributive effects, such as the effects of one's behaviour on other individuals, groups of people or other actors such as firms or institutions. When taking a macro approach, one can study relations between economic aggregates, such as household groups, sectors or institutions. By doing so, one can capture a wide variety of developments and interactions, but often lacking distributional details. The combination of micro and macro approaches allows capturing indirect effects of individual behaviour.

This is precisely what we want to do within the Urban Economics group. Luckily, I can draw from a broad portfolio of skills and modelling experiences that are present within my team.

\section{Micro-insights}

At the micro-level, surveys and in-the-lab or in-the-field behavioural experiments are very useful to collect precise and detailed information on individual persons. We have access to several large-scale surveys. The Dutch WoOn dataset, for example, is a great example of an extensive survey that deals with well-being, spatial preferences and neighbourhood characteristics. Another useful dataset is the British household panel, that follows thousands of individuals and also reports on their well-being, health, spatial location and attitudes towards the environment and climate change. In addition, we can and will collect data ourselves by setting up our own surveys and 
experiments. The advantage of this is that we can ask exactly the right questions of the right persons.

Michel Handgraaf and his team collect, for example, information about energy and water use of students, tourists and residents in Amsterdam and subject some of them to carefully designed behavioural experiments. Respondents receive different or no information about the impact of their water use. By measuring the actual use of water, Michel can analyse which message works best for which kind of persons.

These surveys and experiments result in very rich datasets. However, working with surveys inherently implies that one only collects information about a small part of the total population, the sample. For policymakers, though, it is often much more relevant to understand the impact for an area as a whole, or to see the spatial distribution of effects over neighbourhoods or regions.

\section{From micro to neighbourhoods}

Therefore, I intend to proceed working on the improvement of spatial microsimulation methods. Methods that enable us to combine and scale up results of surveys to a much larger area. Current data availability and GIS techniques increasingly allow scholars to project survey results to, for example, a city as a whole, to neighbourhoods or zip codes (van Leeuwen and Nijkamp, 2009).

However, in the context of the energy transition and a circular society, small differences in the spatial environment can result in large differences in terms of energy use, or recycling behaviour. Therefore, I want to go a step further and allocate projected households to single building blocks in a neighbourhood. For this, I intend to team up with the Dutch Environmental Planning Agency and a yet to be recruited $\mathrm{PhD}$ student. By adding heterogeneity to the population figures, our picture of a city, or a region, becomes much more realistic and academics, as well as policy makers, get the opportunity to assess spatial impacts and inequalities resulting from certain interventions at very small spatial levels.

In addition, we can add (simple) behavioural rules to these people, for example in an agent-based context (Birkin and $\mathrm{Wu}, 2012$ ). Agent-based models are computational models that simulate actions and interactions between agents and their environment. Think for example about residents that consider investing in solar panels. Their choice is likely to be influenced by their budget, environmental attitudes, but also by the physical opportunities that their house offers and what the neighbours think or do. Together with Gert-Jan Hofstede from the Information Technology group and AMS, the Advanced Metropolitan Solutions Institute, we 
have plans to translate this topic into an empirical agent-based model. We hope and expect to find emerging results that we observe in reality, but cannot predict with our traditional economic models.

These approaches allow us to generalize new and detailed insights at every spatial level we are interested in and make it much easier to integrate micro-data into macro models such as regional input-output models and even computational general equilibrium models (van Leeuwen et al., 2017).

\section{Macro perspectives}

The strength of macro models lies in the fact that they look at regions as a whole and the interaction between aggregate groups of sectors and households. Interregional input-output tables depict the flows of goods and services between industries in the economy of a region. In addition, depending on the geographic subdivision, the tables show the effects of a certain shock on the region, on neighbouring regions, or on the national economy (van Leeuwen et al., 2005). They can, for example, show the total impact of a higher demand for local food, and how this impacts local areas, but also international farmers, as well as the foodprocessing and transport sectors in different parts of the world. And if we translate the flows of products into nutrients, or $\mathrm{CO}_{2}$ equivalents, we can map out the regional implications of a higher or lower demand in different sectors, such as the agri-food sector.

\section{Thematically Foci}

Of course, the aforementioned approaches and tools can be applied to many research topics. At the Urban Economics group however, there is a clustering around three main topics.

First of all the energy transition, both at the individual and regional level. As mentioned earlier, Michel Handgraaf, together with Anouk Griffioen and Lieke Dreijerink, look at what kind of interventions are successful in changing people's energy and water consumption. Successfully in the sense that it really changes the behavior the intervention is targeting, but also successful in reducing the total energy use of a person, by also looking at rebound effects, when people compensate their energy saving behavior, such as turning down the heating, by using more energy for other activities, such as taking longer showers. This research is joint work with the Student Hotel and AMS, the Advanced Metropolitan solutions Institute, in which both Michel Handgraaf and I are appointed as Principal Investigators. In this context, I will focus on how neighborhood characteristics impact the opportunities and willingness of residents to either use 
less energy or to invest more in renewable energy. To what extent does it matter what your neighbors do, what kind of initiatives are organized by local citizens or the municipality or how green or aesthetic your environment is?

The second main theme is the circular society and circular agri-food systems. In line with our minister of agriculture, Carola Schouten, we see the importance of circular agri-food systems and in particular the role of consumers. We want to contribute to this important challenge by studying consumer preferences for local or regional products and their willingness to pay (in money or time) for these products, as well as their role in the recycling of waste. Just before summer, Koen van der Gaast, a $\mathrm{PhD}$ student that is also linked to AERES Hogeschool and is co-supervised by Sigrid Wertheim, started looking at the opportunities and pitfalls of a regional food system in Flevoland. He will look at preferences of consumers in Almere and at possible business cases for local entrepreneurs.

At the same time, I also want to take a critical attitude towards the concept of regional food systems, and the impacts at the global level. For this purpose, together with Liesbeth de Schutter, a PhD student who is also affiliated with the University of Vienna, and in cooperation with the Flevocampus we intend to develop a bio-based input-output model for the province of Flevoland to look at the environmental costs and benefits of a regional food system.

Finally, the urban economics group will continue working on healthy and inclusive cities. Recently, Johan van Ophem and two masters students started a Healthy cities project, in which they collect evidence-based studies on challenges and solutions for healthy cities. One focus point is on the relationship between urban green and health at the neighborhood level. On this topic, we also teamed up with Emily de Vet and Annemien Haveman from Strategic Communication.

All in all, a broad research focus, but with a clear Red Thread, namely how spatial factors impact people and places in pursuing sustainable development, and how we can use these insights to promote urban-rural interactions.

\section{Future generations and Teaching}

Wageningen University is not only a research institute, but clearly also a place for teaching and education. Within the urban economics group, we have quite large teaching obligations. In the 11 months since I joined Wageningen University, I experienced that many students are really interested and passionate about their studies and thesis research. As such, I am looking forward to develop the new course of Urban Economics and Analysis, to participate in and update several other 
courses. I also enjoy supervising students during their theses or research projects. This teaching and supervising really enriches and stimulates my personal research as well. An example is work from a Master student that is active in our group, Joris Galema. He looked at the preferences of urban and rural residents for buying and selling second-hand products through the online channel of Marktplaats. His efficient way of collecting observations through the internet made me enthusiastic about looking for new sources of information. Also the ACT group that I supervised and that reported their findings in a very informative and attractive look-book made me think about new ways communicating my results.

\section{Success?}

When do I regard my mission to be successful? When I, together with my fellow Urban Economics colleagues contribute in a critical and constrictive manner to academic and societal debates. First of all, by adding more information about the spatial and social context of individuals and households in our behavioural analyses, and bridging the gap between micro-level outcomes and macro-level results.

Secondly, by advancing the development and evaluation of place-sensitive policies to contribute to inclusive and sustainable cities and an improved collaboration between cities and rural areas. When, as a result, more urban and rural people feel heard and understood by policymakers and the energy transition and circular society become the norm. 


\section{Words of Thanks}

This brings me to my words of thanks. Because, like cities, academics are no islands - at least, they should not be. I am grateful that I am firmly embedded in a great network of colleagues, family and friends.

Before I came to Wageningen University, I spent 16 years in Amsterdam at the VU University and I enjoyed my time there very much. I would like to thank my supervisor Piet Rietveld, who unfortunately passed away, for his emphasis on quality and integrity, and Peter Nijkamp for dragging me into academics and introducing me to many interesting people. I also want to thank the other department members for the great atmosphere that I experienced, and in particular Mark Leijsen and Hadewijch van Delft, for all the coffee and cup-a-soups during the almost 15 years that we spent in the same office.

I am glad that also at Wageningen I found a great working environment. I thank the Rector Magnificus, Arthur Mol, and the university board for appointing me as professor in Urban Economics and chair of the UEC chair group at Wageningen University.

Ekko, Erwin, Justus and Ewout, thank you for welcoming me to the Section Economics and for introducing me to the Wageningen way of management. Michel, Johan, Pierre and Jannette, thank you for making me feel at home in our chair group, I really appreciate your honest interest, criticism and enthusiasm. Karen, Dineke, Betty and Tjitske, thank you for supporting me in my new tasks. Jack van der Vorst, you told me to also look outside the border of the Section and even the Social Sciences group. I am happy that I could already team up with Emily de Vet, Gert-Jan Hofstede, Sigrid Wertheim, Peter Oosterveer, Tamara Metze, Martha Bakker, Bas van Vliet, Huub Rijnaarts, Jouke Dykstra and several others. I look forward to many years of cooperation in the future.

Finally, I would also like to thank my friends and colleagues from the Regional Science Association International. Thank you for showing how academic life should be, for sharing your inspiring research and for the great fun we have had during several conferences and other activities. I am honoured that some of you came all the way from the US, UK, Austria and even from Groningen.

I also would like to thank friends and family: my old study friends from Wageningen, my new friends from the church and the Lions group in MaarnMaarsbergen. Thank you for distracting me from work to do things that equally matter. I would also like to thank my family: without the enthusiasm and support 
of you all I could never have reached this point in my career and at the same time enjoy enough precious time with our twins, Veerle and Joan. Hannes, thank you for equality-equality in terms of the importance of our careers, and equality in terms of responsibilities at home. En Veerle en Joan, jullie zijn geweldig. En nu is het eindelijk tijd voor mijn professor feest!

Meneer de rector, ik heb gezegd!

\section{References}

Anas, A., Arnott, R., \& Small, K. A. (1998). Urban spatial structure. Journal of economic literature, 36(3), 1426-1464.

Christaller, W. (1966). Central Places in Southern Germany. translated C.W. Baskin. Englewood, NJ: Prentice Hall.

Birkin, M., \& Wu, B. (2012). A review of microsimulation and hybrid agent-based approaches. In Agent-based models of geographical systems (pp. 51-68). Springer, Dordrecht.

Dijkstra, L., Garcilazo, E., \& McCann, P. (2015). The effects of the global financial crisis on European regions and cities. Journal of Economic Geography, 15(5), 935-949.

Garretsen, H., \& Marlet, G. (2017). Amenities and the attraction of Dutch cities. Regional Studies, 51(5), 724-736.

Gladek, E., T. Thorin, L. Verkooijen, V. Shirochenkova, \& S. Quigley (2017). Circular Amsterdam: Spatial Implications. Metabolic, Amsterdam.

Glaeser, E. (2011). Triumph of the City. Pan Macmillan.

Gruber, S., \& Soci, A. (2010). Agglomeration, agriculture, and the perspective of the periphery. Spatial Economic Analysis, 5(1), 43-72.

Helpman, E. (1998). The size of regions. In D. Pines, E. Sadka, \& I. Zilcha (Eds.), Topics in public economics: Theoretical and applied analysis (pp. 33-54). Cambridge: Cambridge University Press.

Herslund, L. (2012). The rural creative class: counterurbanisation and entrepreneurship in the Danish countryside. Sociologia Ruralis, 52(2), 235-255.

Huddart-Kennedy, E., Beckley, T. M., McFarlane, B. L., \& Nadeau, S. (2009). Rural-urban differences in environmental concern in Canada. Rural sociology, 74(3), 309-329.

Jackson T. (2005), Motivating Sustainable Consumption. A review of evidence on consumer behaviour and behavioural change, A report for the Sustainable Development Research Network (SDRN), from www.sustainablelifestyles.ac.uk/sites/default/files/motivating_sc_final.pdf 
Koster, E. M., de Gelder, R., Di Nardo, F., Williams, G., Harrison, A., van Buren, L. P., ... \& Achterberg, P. W. (2017). Health status in Europe: comparison of 24 urban areas to the corresponding 10 countries (EURO-URHIS 2). The European Journal of Public Health, 27(suppl_2), 62-67.

Krugman, P. 1991. Increasing returns and economic geography. Journal of Political Economy, 99: 483-99.

Leeuwen, E.S. van (2010). Urban-rural interactions. Towns as focus points in rural development. Springer, Heidelberg.

Leeuwen, E.S. van (2015). Urban-Rural Synergies: An Explorative Study at the NUTS $_{3}$ Level. Applied Spatial Analysis and Policy, 8(3), 273-289.

Leeuwen, E.S. van, \& Rietveld, P. (2011). Spatial consumer behaviour in small and medium-sized towns. Regional Studies, 45(8), 1107-1119.

Leeuwen, E.S. van, Clarke, G., Hermannsson, K., \& Swales, K. (2017). Potentials and Prospects for Micro-Macro Modelling in Regional Science. In Regional Research Frontiers-Vol. 2 (pp. 105-123). Springer, Cambridge.

Leeuwen, E.S., van, \& Nijkamp, (2010). A microsimulation model for e-services in cultural heritage tourism. Tourism Economics, 16(2), 361-384.

Leeuwen, E.S. van, Nijkamp, P. \& Rietveld, P., (2005). Regional Input-Output Analysis. In: Kempf-Leonard. K. (Ed.), Encyclopedia of Social Measurement, Elsevier: $317-323$

Lichter, D. T., \& Brown, D. L. (2011). Rural America in an urban society: Changing spatial and social boundaries. Annual review of sociology, 37, 565-592.

Molloy, R., Smith, C. L., \& Wozniak, A. (2011). Internal migration in the United States. Journal of Economic perspectives, 25(3), 173-96.

OneNYC (2018). OneNYC Progress Report 2018. New York Government. https:// onenyc.cityofnewyork.us

Puga D (2010) The magnitude and causes of agglomeration economies. Journal of Regional Science 50: 203-219

Sarvilinna, A., Lehtoranta, V., \& Hjerppe, T. (2018). Willingness to participate in the restoration of waters in an urban-rural setting: Local drivers and motivations behind environmental behavior. Environmental Science $\mathcal{E}$ Policy, 85, 11-18.

Silva, A., Rosano, M., Stocker, L., \& Gorissen, L. (2017). From waste to sustainable materials management: Three case studies of the transition journey. Waste management, 61, 547-557.

Sørensen, J. F. (2014). Rural-urban differences in life satisfaction: Evidence from the European Union. Regional Studies, 48(9), 1451-1466.

De Souza, P. (2017). The Rural and Peripheral in Regional Development: An Alternative Perspective. Routledge.

Stern, P 2000. Toward a Coherent Theory of Environmentally Significant Behavior. 
Journal of Social Issues, 56(3), 407-424.

Terluin, I. J. (2003). Differences in economic development in rural regions of advanced countries: An overview and critical analysis of theories. Journal of Rural Studies, 19, 327-344.

Thünen, von (1826). Der Isolierte Staat. Beziehung auf landwrirtschaft und Nationalekonomie.

UNEP (2018). Towards a green economy: pathways to sustainable development and poverty eradication. United Nations Environment Programme. 



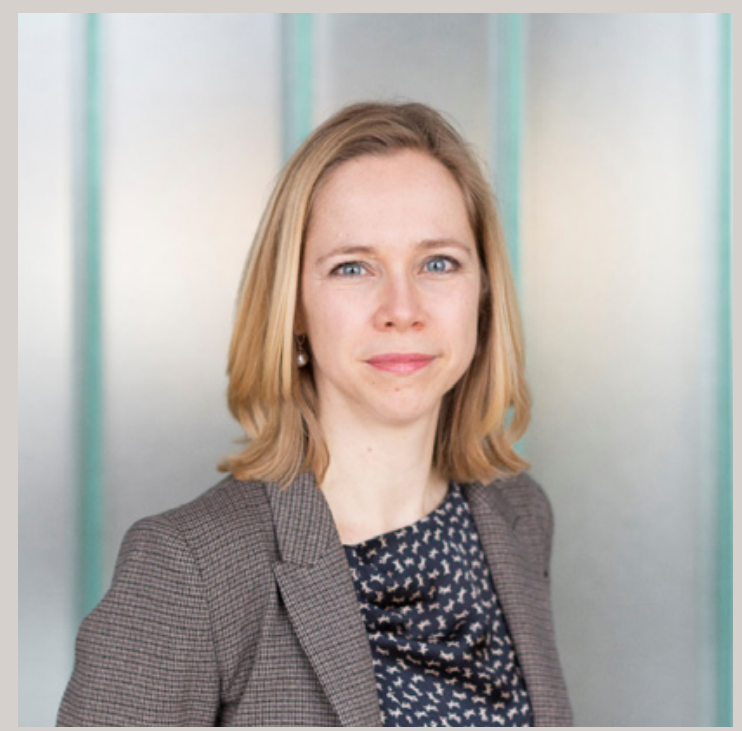

Prof.dr Eveline S. van Leeuwen

'Cities are always connected to rural regions. Optimizing these interactions will be beneficial to both in terms of political stability, energy prosumption and nutrient balances. However, the fact that academics and decision-makers are mostly urbanites condition their perceptions of rural areas and their potential for our future. Therefore, "in order to promote urban-rural interactions, we need to create better insights in urban-rural differences". We need to combine micro- and macro insights to advance the development and evaluation of place-sensitive policies to contribute to inclusive and sustainable cities and an improved collaboration between cities and rural areas.' 